\title{
Hospitalizations for
} gastrointestinal and

\section{cardiovascular events in the CADEUS cohort of traditional or Coxib NSAID users}

\section{Correspondence}

Professor Nicholas Moore, MD, PhD, FRCP FISPE, Département de Pharmacologie, Université Victor Segalen Bordeaux 2, 146 Rue Léo Saignat, 33076 Bordeaux cedex, France.

Tel: + 33 (0)5 57571560

Fax:+ 33 (0)5 57574671

E-mail:

nicholas.moore@pharmaco.u-bordeaux2.fr

\section{Keywords}

cardiovascular events, cohort, coxib, gastrointestinal toxicity, NSAID

\section{Received}

23 July 2009

Accepted

16 October 2009

\section{WHAT IS ALREADY KNOWN ABOUT} THIS SUBJECT

- Traditional or COX-2-specific (coxib) nonsteroidal anti-inflammatory drugs (NSAIDs) are widely used.

- Their use is associated with gastrointestinal toxicity and cardiovascular events.

\section{WHAT THIS STUDY ADDS}

- The low event rates observed for gastrointestinal bleeding and myocardial infarction in the real-life conditions of NSAID use (traditional and coxib) in France preclude their exploration using realistic field studies.

- Large population healthcare databases are required to study such risks.

\section{AIMS}

To assess hospital admission rates for gastrointestinal (GI) or cardiovascular (CV) events in real-life use of nonsteroidal anti-inflammatory drugs (NSAIDs).

\section{METHODS}

CADEUS is a real-life population-based cohort study of 23535 coxib (celecoxib or rofecoxib) and 22919 traditional NSAID (tNSAID) users. Each hospitalization reported between index day (NSAID delivery) and questionnaire submission (median $=75$ days) was explored using hospital discharge summaries. An expert committee validated blindly serious $\mathrm{Gl}$ and $\mathrm{CV}$ events according to predefined criteria.

\section{RESULTS}

Coxib users were older and had more GI history than tNSAID users. There were 21 hospitalizations for Gl events, 12 in the coxib cohort and nine in the tNSAID cohort (respectively one and three upper GI haemorrhages and no ulcer perforations). Rates of $\mathrm{Gl}$ events were 0.39 per 1000 patients [ $95 \%$ confidence interval $(\mathrm{Cl}) 0.18,0.75]$ for tNSAID users and 0.51 per 1000 patients $(95 \% \mathrm{Cl} 0.26$, 0.89) for coxib users. There were 21 hospitalizations for CV events, 13 in the coxib cohort and eight in the tNSAID cohort. None was fatal. Rates of CV events were, respectively, $0.59(95 \% \mathrm{Cl} 0.24,1.22), 0.51$ (95\% Cl $0.19,1.11)$ and 0.35 (95\% $\mathrm{Cl} 0.15,0.69)$ per 1000 patients for celecoxib, rofecoxib and tNSAIDs. GI or CV event rates were not different between products even for patients $>60$ years old.

\section{CONCLUSIONS}

Hospitalization rates for GI bleeding were 10-20 times lower than expected from published randomized clinical trials, probably because of differences in drug usage and concomitant gastroprotection. CV event rates conformed to those expected from general population data. These results emphasize the necessity of developing population healthcare databases to explore such low event rates. 


\section{Introduction}

Nonsteroidal anti-inflammatory drugs (NSAIDs) are widely used for various indications, mostly in rheumatology. In the USA, $10-20 \%$ of the subjects $>65$ years old are treated with NSAIDs [1,2] and many others are self-medicated. A similar level of use has been reported in the French population [3-5].

Over the years, these drugs have raised many concerns regarding potential toxicity. Of all the adverse effects of NSAIDs, those that have received the most attention are gastrointestinal (Gl) toxicity and, more recently, cardiovascular (CV) events. The Gl toxicity of NSAIDs has been explored in a large number of epidemiological studies $[6,7]$ and clinical trials [8,9]. Gastroprotective agents (GPAs) have been used to reduce the gastrotoxicity of NSAIDs, initially the poorly tolerated misoprostol [10], or the $\mathrm{H} 2$ antagonists [11]. Nowadays the preferred gastroprotection is mostly with proton pump inhibitors $[12,13]$. However, poor compliance with gastroprotection may lead to persistent risk [14]. This led to the development of the more selective cyclooxygenase- 2 inhibitors celecoxib and rofecoxib, which seemed to have a reduced GI toxicity compared with traditional nonselective NSAIDs (tNSAIDs) $[15,16]$.

However, the development of these drugs led to the identification of a possible CV risk [17], and the withdrawal from the market of rofecoxib.

At the time of their marketing in France, it was expected that the use of celecoxib and rofecoxib might affect Gl event risk.This and the emergent $\mathrm{CV}$ concerns led the public authorities to request a large-scale drug utilization study. The primary aim of this study, CADEUS [18], was to describe usage patterns for tNSAIDs and coxibs [19]. In the absence of data concerning real-life rates of $\mathrm{Gl}$ and $\mathrm{CV}$ events among NSAID users in France, it was not possible to power the CADEUS study to compare $\mathrm{Gl}$ and $\mathrm{CV}$ event rates between coxibs and tNSAIDs. A pilot study was therefore built into the CADEUS drug utilization study to provide preliminary estimates of event rates and evaluate the feasibility of a second study designed to compare CV and Gl risks (CADERIS).The results of this pilot study are presented here.

\section{Methods}

From September 2003 to August 2004, the CADEUS cohort was constituted using the French National Healthcare Insurance System for salaried persons (CNAM-TS) database, as previously described [18]. Briefly, each month subjects were randomly sampled without replacement within the database of the CNAM-TS by using the following criteria: (i) patients living in metropolitan France; (ii) age $\geq 20$ years, alive, with a valid address; (iii) who submitted a claim for an NSAID dispensation (celecoxib, rofecoxib or tNSAIDs) during the month preceding their sampling date; (iv) with at least one reimbursed healthcare expense during the 6 months before the dispensation on which the patient was selected; $(v)$ with valid prescriber's name and address; (vi) not previously sampled within this study. Eligible patients had received at least one dispensation (initial or renewal) of celecoxib, rofecoxib or tNSAIDs, and the date of this dispensation was the index date for the study. The objective of the study was to identify three parallel cohorts of 10000,10000 and 20000 patients, respectively. The number of patients contacted was adjusted on response rates to obtain the desired final patient numbers. There was no difference between patients who agreed to participate in the study and those who did not respond or declined [18].

Self-administered questionnaires were sent between 8 and 12 weeks following the index date. Patients and their physicians were asked to report all hospitalizations and specialist consultations that occurred after the index date (date, motive, place). The observation period for hospitalization occurrence was the delay between the NSAID dispensation and completion of patient self-questionnaire. Only data concerning patients who accepted to participate were included in the study. There was no difference between patients whose prescriber responded and those whose prescriber did not [20].

All hospitalizations were presented to an expert committee composed of one general practitioner, one gastroenterologist, one cardiologist, one rheumatologist, one pharmacologist and one neurologist, blinded to tNSAID or coxib treatment. Hospitalizations that the expert committee considered to be certainly not related to a CV or Gl event were excluded (e.g. hip replacement, depression, etc.). For all other hospitalizations, discharge summaries were requested and examined blindly of NSAID treatment received by the expert committee, and further information was sought if requested by the expert committee.

Events leading to hospitalization were classified according to predefined criteria adapted from Bombardier et al.[15].The Gl events that were considered were: (i) acute upper Gl haemorrhage defined as haematemesis and/or melaena witnessed by the patient or a healthcare provider with endoscopic or surgical evidence of recent bleeding; (ii) acute lower intestinal haemorrhage defined as rectorrhagia witnessed by the patient or a healthcare provider with endoscopic or surgical evidence of recent bleeding; (iii) perforated ulcer assessed on endoscopic or surgical evidence; or (iv) evidence of upper or lower digestive ulcer on endoscopic and/or surgical examination. Complicated ulcer was defined in the case of bleeding or perforation.

The CV events that were considered were: (i) unstable or accelerated angina: spontaneous or worsening anginal chest pain, or ECG with abnormal repolarization and no Q-wave and increased troponin without increased creatine phosphokinase, muscle band (CPK-MB); (ii) myocardial infarction: spontaneous anginal pain and Q-wave on the ECG or troponin and CPK-MB increase; (iii) peripheral arterial thrombosis: livid limb or absent pulse distal to occlusion 
and/or sudden pain with impotence, and confirmatory imaging (ultrasound or angiography); (iv) stroke: focal neurological signs lasting $>24 \mathrm{~h}$ with confirmatory imaging (magnetic resonance imaging or computed tomography scan).

Based on all documentation available (hospital discharge summaries, endoscopy, surgical reports, ECG, imaging reports, etc.), events were classified as confirmed or not.

The protocol was submitted to and accepted by the French National Data-Protection Commission in charge of authorizing data-processing (Commission Nationale de I'Informatique et des Libertés) and the French National Council of Physicians (Conseil National de I'Ordre des Médecins). All patients gave written informed consent.

\section{Statistical analysis}

Because of low variation of the follow-up period duration between subjects (i.e. the delay between the index date and return of questionnaires), cumulative rates of events were estimated. Overall rates for tNSAID and coxib users separately are presented as well as rates stratified according to age ( $<60$ years and $\geq 60$ years). All rates are per thousand patients in the cohorts, presented with their exact 95\% Poisson confidence intervals (Cl). Betweenproduct comparisons of rates relied on exact tests. Analyses were performed using $\mathrm{SAS}^{\circledR}$, version 8.1 (SAS Institute, Cary, NC, USA) and StatXact-7 (Cytel Software Corp., Cambridge, MA, USA).

\section{Results}

\section{Study population}

The description of the main CADEUS study population and drug utilization have been reported elsewhere $[18,19]$. Completed questionnaires were obtained from $32.6 \%$ of prescribers and $20.8 \%$ of patients contacted. There were no differences between responder and nonresponder patients [18], nor between patients with responding or nonresponding prescribers [20]. Among the 46454 patients who returned a completed questionnaire and were included in the CADEUS study [18], 23535 belonged to the coxib cohorts (11780 in the celecoxib cohort and 11755 in the rofecoxib cohort) and 22919 to the tNSAID cohort (Table 1). Among the tNSAIDs users, $27.4 \%$ were prescribed ibuprofen on index date, $13.4 \%$ piroxicam, $12.4 \%$ ketoprofen, $11.2 \%$ diclofenac, $7.7 \%$ naproxen, $5.9 \%$ tiaprofenic acid. Other tNSAIDs were prescribed to $<5 \%$ of the population each. There were no differences between the celcoxib and rofecoxib cohorts. Coxib users were older (mean age 63.5 years, with $62.8 \%>60$ years) than the tNSAID users ( 49.5 years with $27.9 \%>60$ years). Sex ratio was similar in the coxib and tNSAID cohorts. Previous GI disorders were more often reported by coxib users (43.2\%) than by tNSAID users (35.0\%). The apparent contrast between tNSAIDs and coxibs for previous CV history disappears after adjustment for age [19]. Indication profiles were different between the two cohorts: $>50 \%$ of the coxib users were treated for osteoarthritis, whereas this was the case for $<20 \%$ of tNSAID users; $<2 \%$ of coxib users were treated for nonrheumatic indications, whereas it was the main indication for tNSAIDs (33.8\%). Co-prescription of GPAs was found in approximately one-quarter of both coxib and tNSAID users and concomitant low-dose aspirin was found in $8.2 \%$ of coxib and $3.8 \%$ of tNSAID users [19].

\section{Hospitalized GI and CV events}

The median delay between the index NSAID dispensation and completion of patient self-questionnaire was 75.5 days for coxib subjects [interquartile range (IQR) 66-87 days) and 74.0 days for tNSAID subjects (IQR 64-85 days). Of the 1780 hospitalizations reported by the 46454 patients, the expert committee retained 732 hospitalizations for investigation of Gl or CV events. Hospital discharge summaries were obtained for 688 (94\%) of them. After examination of hospital discharge summaries and other available information, $21 \mathrm{CV}$ and $21 \mathrm{Gl}$ events were confirmed by the expert committee (diagnoses detailed in Table 2).

Most CV events were unstable/accelerated angina or myocardial infarction (10 in the coxib and three in the tNSAID cohorts). The overall rates of hospitalized CV events were 0.55 per 1000 patients $(95 \% \mathrm{Cl} 0.29,0.94)$ for coxib users and 0.35 per 1000 patients $(95 \% \mathrm{Cl} 0.15,0.69)$ for tNSAID users. All but one CV event in coxib users and half of those in tNSAID users occurred in patients aged $\geq 60$ years. Rates of unstable/accelerated angina and myocardial infarction combined did not differ significantly between coxib and tNSAID users $(P=0.4175)$.

Of the six rofecoxib users with a confirmed serious $C V$ event, one was female, five were aged $\geq 60$ years, all had previous CV history and indications were osteoarthritis $(n=$ $4)$ and back pain $(n=2)$. Of the seven celecoxib users with a serious CV event, three were female, all were aged $\geq 60$ years, all had previous CV history and indications were osteoarthritis $(n=1)$, inflammatory arthritis $(n=3)$ and back pain $(n=3)$. Of the eight tNSAID users, one was female, four were aged $\geq 60$ years, all but one had previous CV history, and indications were osteoarticular pain $(n=2)$, osteoarthritis $(n=3)$, inflammatory rheumatism $(n=1)$ and 'other' pain $(n=2)$.

Most Gl events were noncomplicated ulcers (eight in the coxib and five in the tNSAID cohorts). The overall rates of hospitalized Gl events were 0.39 per 1000 patients (95\% $\mathrm{Cl} 0.18,0.75)$ for tNSAID users and 0.51 per 1000 patients $(95 \% \mathrm{Cl} 0.26,0.89)$ for coxib users. Rates were about five (tNSAID users) to 10 (for coxib users) times higher among those aged $\geq 60$ years than in patients $<60$ years old. Agestratified event rates were roughly similar between coxib and tNSAID users, with no significant difference $(P=$ 0.7086). There was no clear difference between users of rofecoxib or celecoxib. 


\section{Table 1}

Characteristics of the 46454 patients included in the CADEUS study

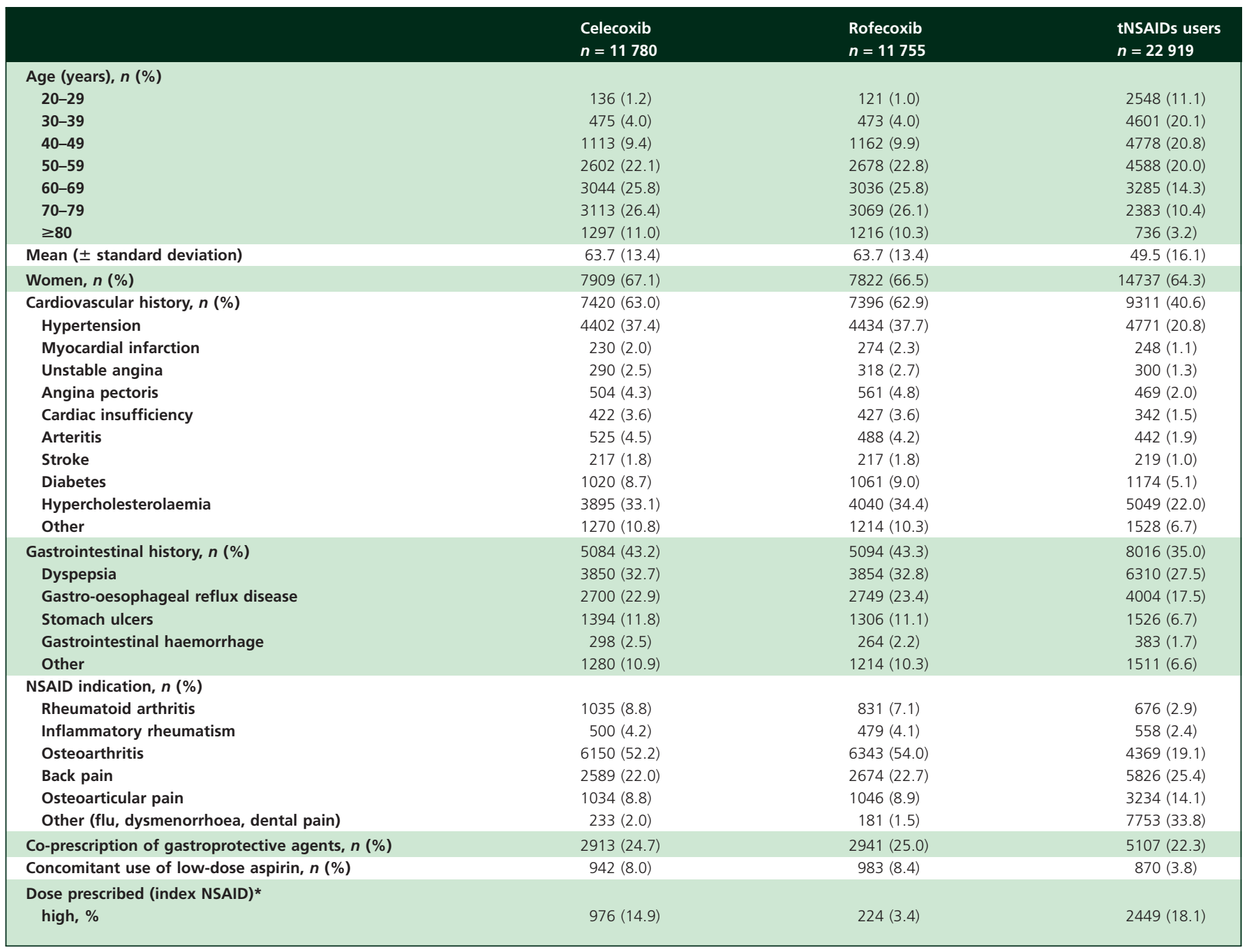

*Populations with available data: celecoxib $n=6537$, rofecoxib $n=6528$, tNSAIDs $n=13$ 553, high dose based on Moride et al. 2005 [37].

Of the 12 coxib users with a confirmed severe Gl event, eight were female, 11 were aged $\geq 60$ years, 10 had previous GI history, eight had concomitant GPAs and indications were osteoarthritis $(n=10)$, inflammatory rheumatism $(n=$ 1) and rheumatoid arthritis $(n=1)$.

Of the nine tNSAID users with a confirmed severe Gl event, eight were female, six were aged $\geq 60$ years, six had previous Gl history, three had concomitant GPA and the indications were osteoarthritis $(n=3)$, 'other' pain $(n=3)$, back pain $(n=2)$ and rheumatoid arthritis $(n=1)$.

\section{Discussion}

In this study of over 46000 NSAID users (half traditional, half coxibs), we identified 21 hospitalizations for Gl events and the same number for CV events over a median follow-up of 75 days. Only four of the $21 \mathrm{Gl}$ events were complicated upper Gl ulcer bleeding and 13 of the $21 \mathrm{CV}$ events were myocardial infarction or accelerated angina. None of these events was fatal, as expected from the study design, since patients had to be able to respond to the study to be included, a limitation of this study. However, considering the fatality rates for $\mathrm{Gl}$ events $(<10 \%$ for NSAID-induced upper GI haemorrhage [21]), we do not expect that any missed fatalities would have materially altered the observed event rates, or that this number might have been $>1$. Indeed, had there been missed fatal GI bleeds then there should have been correspondingly more nonfatal hospital admissions to the ratio of $>10$ nonfatal bleeding episodes to one missed fatal. The same reasoning would be true for CV events.

Although only $21 \%$ of all patients contacted for this study agreed to participate, there was no difference in age 
Table 2

Gastrointestinal and cardiovascular events

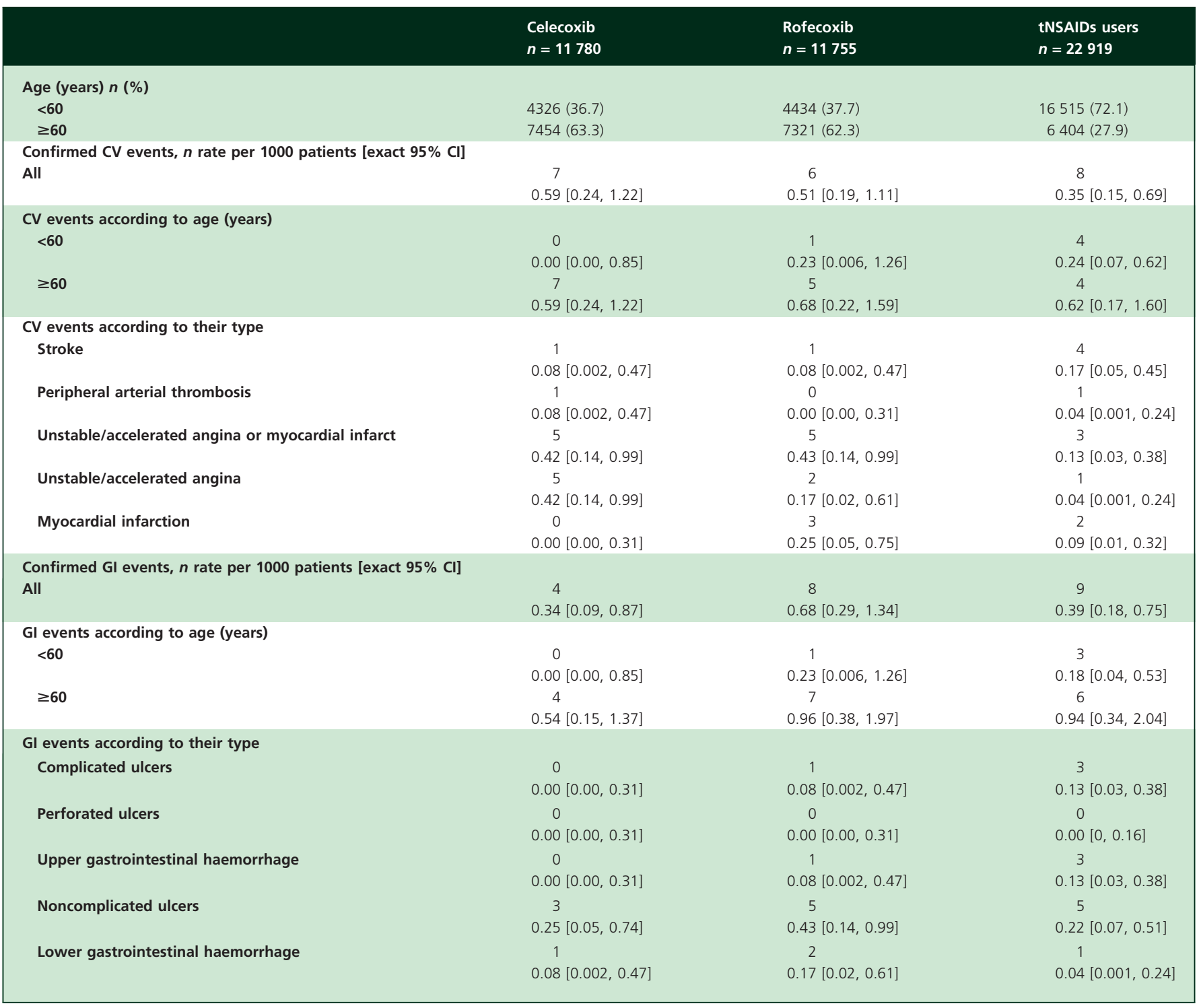

or other main characteristics between those who accepted and those who did not [18]. We cannot surmise that having been hospitalized would be a reason for participating or not. Actually being in the hospital at the time of the study might prevent the patient from responding. However, we suspect that having been hospitalized might even increase the response rate, although we have no information on the expected number of all-cause hospital admissions in this patient group in order to substantiate this hypothesis. Each reported hospital admission was considered by the expert committee and any suspected Gl event was thoroughly investigated. Discharge summaries were obtained for $>94 \%$ of all those that could be related to Gl or CV events. Over 700 hospitalizations were thus assessed by the expert committee using prespecified criteria that were as identi- cal as possible to the criteria for event adjudication in clinical trials or other epidemiological studies. Using these criteria $[15,16]$, four upper Gl bleeds in almost 3.5 million patient-days (9545 patient-years) among $21 \mathrm{Gl}$ events leading to hospitalization were found. Had the event rates been the same as those seen in clinical trials of coxibs and NSAIDS, one would have expected 10-20 times more events $[15,16]$.

The time frame for capturing adverse events, whether it be GI haemorrhage or myocardial infarction, could also be discussed according to different hazard function hypotheses. Although some have suggested a higher Gl risk at onset of NSAID treatment, followed by a decrease related to depletion of susceptibles [22], the event occurrence curves in VIGOR and CLASS shows essentially a linear 
hazard function over the 1-year timeframe of these studies $[15,16]$. The same is true for the CV risk attributed to rofecoxib [23]: although initially it was stated that the risk increased vs. placebo after a year of treatment, further analysis has shown a risk that is apparent from the beginning of high-dose treatment with rofecoxib [24]. The observation time frame for this study was 75 days, which is consistent with the onset of GI or CV risk for new users under depletion of susceptibles hypotheses, and would also capture events occurring after long-term use if the hazard functions are constant. However, the number of events captured is too low to form a conclusion.

An underreporting bias is unlikely because patients were requested to report all hospitalizations, almost all of which were explored and assessed. Uncomplicated ulcers may be treated on an outpatient basis, but in France only $16 \%$ of $\mathrm{Gl}$ haemorrhages are seen as outpatients [21]. Therefore, for a nonreporting bias to explain the findings reported here, i.e. that the rate in real life is 10 times lower than in clinical trials, it would have to affect $>90 \%$ of patients hospitalized with upper GI bleeds, which appears most unlikely considering the very high number and diversity of hospitalizations reported. Such a difference could be related to a different patient mix, including many patients with NSAIDs for common pain or nonrheumatic diseases, especially with tNSAIDs, compared with patients with osteoarthritis or rheumatoid arthritis in the clinical trials. Over $90 \%$ of coxib users were treated for chronic rheumatic diseases (osteoarthritis, rheumatoid arthritis or other inflammatory rheumatism) [19], whereas all patients in the CLASS [16] and VIGOR [15] trials were treated for chronic rheumatic diseases. In the tNSAID patients, three out of nine $\mathrm{Gl}$ events, all uncomplicated ulcers, occurred in the $20 \%$ of all patients treated for osteoarthritis. Of the upper Gl bleeds, one occurred in a patient with rheumatoid arthritis, whereas rheumatoid arthritis and other inflammatory rheumatisms represented approximately $5.3 \%$ of the tNSAID population. The two cases of upper GI bleeding occurred in patients with chronic back pain, presumably osteoarthritis, whereas back pain represented about $25 \%$ of the tNSAID patients. Recomputing event rates on these subpopulations of patients with rheumatology indications did not materially change the event rates, which remained below one per thousand users. Even restricting the analysis to patients $>60$ years old, most of whom had osteoarthritis, did not change the picture; four of five uncomplicated ulcers and only one of three upper Gl bleeds occurred in patients $>60$ years old. A population-based study of hospitalizations for upper Gl bleeding in France [21] found a risk of hospitalization for upper GI bleeding of 0.06 per thousand over 75 days, i.e. only about half of that found here in tNSAID users and thus even further apart from rates in clinical trials. Other pharmacoepidemiological studies have found similar results $[25,26]$. This manifold lower risk of upper $\mathrm{Gl}$ bleeding or other $\mathrm{Gl}$ events or death from $\mathrm{Gl}$ causes between real-life experience with NSAIDs and clini- cal trials was also found in other systematic comparisons of clinical trials and population-based studies [8, 27]. In CADEUS, this might be due to the common use of GPAs, which reached $\geq 60 \%$ in patients with chronic rheumatic diseases [18, 19], whereas GPAs are usually not allowed in clinical trials. Considering the difference in event rates between tNSAIDs and coxibs in this pilot study, and the impact of different biases (channelling, prescription bias, etc.), one would need to study several hundred thousand persons or more to try to demonstrate a possible benefit of coxibs against tNSAIDs in these real-life conditions.

The same reasoning holds for the CV events: from the clinical trials and other epidemiological data, one would expect a 2.8-5-fold higher rate of CV ischaemic events in high-dose rofecoxib users than in users of other NSAIDs $[17,28,29]$. Studies have also found that other NSAIDs seem associated with a slightly elevated risk of myocardial infarction [28]. Our results cannot confirm or refute these findings. The rates of myocardial infarction and accelerated angina were similar to those expected from ischaemic heart disease rates in France when accounting for age and geographical location [30-33]. There was little use of highdose rofecoxib, which was never marketed in France in the 50-mg tablets. Although we can reasonably confidently exclude a major difference in risk of coronary heart disease between the patient cohorts, we cannot exclude a small increase in risk such as that found in other epidemiological studies. Exploring such small excess risks in NSAID users would require inclusion of several hundred thousand patients. This is not feasible in field studies such as that presented here. To do such large studies, one has to be able to access large population databases containing healthcare data, such as those that exist in the USA or the UK (e.g. the General Practice Research Database [34]). Their absence in France precludes any such large studies in this country at this time. These would, however, be most useful to answer specific questions pertaining to the NSAIDrelated risk in France, where the incidence of ischaemic heart disease is notoriously low, possibly related to the drinking of red wine [35] and perhaps certain spirits [36].

\section{Conclusions}

This pilot study has shown that the actual event rates for $\mathrm{Gl}$ bleeding and myocardial infarction in the real-life conditions of NSAID use (traditional and coxib) in France are much lower than in clinical trials, which precludes their exploration using realistic field studies. This underlines the need to develop large population health databases throughout Europe such as the General Practice Research Database in the UK.

\section{Competing interests}

None to declare. 
The authors thank all patients and physicians who agreed to participate in this study. We also wish to thank the very helpful and willing persons who contributed to the study, the list of whom can be found at the following address: http:// www.pharmacologie.u-bordeaux2.fr/Cadeus/. The critical events committee was composed of: P. Le Metayer, D. Laharie, J-L. Demeaux, I. Sibon, F. Yekhlef, B. Biolsi, G. Miremont-Salamé and T. Schaeverbeke. This study was funded by unconditional grants from Merck \& Co. and Pfizer Inc. Neither had any role in study design, in data collection, analysis or interpretation, or in writing the report. The CADEUS study was conducted under a partnership agreement between Caisse Nationale d'Assurance Maladie des Travailleurs Salariés, Direction Générale de la Santé, Comité Economique des Produits de Santé, Merck \& Co., Pfizer Inc., and Université Victor Segalen Bordeaux 2.

\section{REFERENCES}

1 Chrischilles EA, Lemke JH, Wallace RB, Drube GA. Prevalence and characteristics of multiple analgesic drug use in an elderly study group. J Am Geriatr Soc 1990; 38: 979-84.

2 Talley NJ, Evans JM, Fleming KC, Harmsen WS, Zinsmeister AR, Melton LJ 3rd. Nonsteroidal antiinflammatory drugs and dyspepsia in the elderly. Dig Dis Sci 1995; 40: 1345-50.

3 Moore N. Place of OTC analgesics and NSAIDs in osteoarthritis. Inflammopharmacology 2003; 11:355-62.

4 Moore N, Verschuren X, Montout C, Callens J, Kong SX, Begaud B. Excess costs related to non-steroidal anti-inflammatory drug utilization in general practice. Therapie 2000; 55: 133-6.

5 Salles-Montaudon N, Fourrier A, Dartigues JF, Rainfray M, Emeriau JP. [Evolution of drug treatments in the aged living at home]. Rev Med Interne 2000; 21:664-71.

6 Henry D, Lim LL, Garcia Rodriguez LA, Perez Gutthann S, Carson JL, Griffin M, Savage R, Logan R, Moride Y, Hawkey C, Hill S, Fries JT. Variability in risk of gastrointestinal complications with individual non-steroidal anti-inflammatory drugs: results of a collaborative meta-analysis. BMJ 1996; 312: 1563-6.

7 Henry D, McGettigan P. Epidemiology overview of gastrointestinal and renal toxicity of NSAIDs. Int J Clin Pract Suppl 2003; 43-9.

8 Tramer MR, Moore RA, Reynolds DJ, McQuay HJ. Quantitative estimation of rare adverse events which follow a biological progression: a new model applied to chronic NSAID use. Pain 2000; 85: 169-82.

9 Wolfe MM, Lichtenstein DR, Singh G. Gastrointestinal toxicity of nonsteroidal antiinflammatory drugs. N Engl J Med 1999; 340: 1888-99.

10 Graham DY, Agrawal NM, Roth SH. Prevention of NSAID-induced gastric ulcer with misoprostol: multicentre, double-blind, placebo-controlled trial. Lancet 1988; 2: 1277-80.
11 Raskin JB, White RH, Jaszewski R, Korsten MA, Schubert TT, Fort JG. Misoprostol and ranitidine in the prevention of NSAID-induced ulcers: a prospective, double-blind, multicenter study. Am J Gastroenterol 1996; 91: 223-7.

12 Hawkey CJ, Karrasch JA, Szczepanski L, Walker DG, Barkun A, Swannell AJ, Yeomans ND. Omeprazole compared with misoprostol for ulcers associated with nonsteroidal antiinflammatory drugs. Omeprazole versus Misoprostol for NSAID-induced Ulcer Management (OMNIUM) Study Group. N Engl J Med 1998; 338: 727-34.

13 Leontiadis GI, Sreedharan A, Dorward S, Barton P, Delaney B, Howden CW, Orhewere M, Gisbert J, Sharma VK, Rostom A, Moayyedi P, Forman D. Systematic reviews of the clinical effectiveness and cost-effectiveness of proton pump inhibitors in acute upper gastrointestinal bleeding. Health Technol Assess 2007; 11: iii-iv, 1-164.

14 Moore RA, Derry S, Phillips CJ, McQuay HJ. Nonsteroidal anti-inflammatory drugs (NSAIDs), cyxlooxygenase-2 selective inhibitors (coxibs) and gastrointestinal harm: review of clinical trials and clinical practice. BMC Musculoskelet Disord 2006; 7: 79.

15 Bombardier C, Laine L, Reicin A, Shapiro D, Burgos-Vargas R, Davis B, Day R, Ferraz MB, Hawkey CJ, Hochberg MC, Kvien TK, Schnitzer TJ. Comparison of upper gastrointestinal toxicity of rofecoxib and naproxen in patients with rheumatoid arthritis. VIGOR Study Group. N Engl J Med 2000; 343: 1520-8, 2 p following 28.

16 Silverstein FE, Faich G, Goldstein JL, Simon LS, Pincus T, Whelton A, Makuch R, Eisen G, Agrawal NM, Stenson WF, Burr AM, Zhao WW, Kent JD, Lefkowith JB, Verburg KM, Geis GS. Gastrointestinal toxicity with celecoxib vs nonsteroidal anti-inflammatory drugs for osteoarthritis and rheumatoid arthritis: the CLASS study: A randomized controlled trial. Celecoxib Long-term Arthritis Safety Study. JAMA 2000; 284: 1247-55.

17 McGettigan P, Henry D. Cardiovascular risk and inhibition of cyclooxygenase: a systematic review of the observational studies of selective and nonselective inhibitors of cyclooxygenase 2. JAMA 2006; 296: 1633-44.

18 Depont F, Fourrier A, Merliere Y, Droz C, Amouretti M, Begaud B, Benichou J, Moride Y, Blin P, Moore N. The CADEUS study: methods and logistics. Pharmacoepidemiol Drug Saf 2007; 16: 571-80.

19 Depont F, Fourrier A, Merliere Y, Droz C, Amouretti M, Begaud B, Benichou J, Moride Y, Velo GP, Sturkenboom M, Blin P, Moore N. Channelling of COX-2 inhibitors to patients at higher gastrointestinal risk but not at lower cardiovascular risk: the Cox2 inhibitors and tNSAIDs description of users (CADEUS) study. Pharmacoepidemiol Drug Saf 2007; 16: 891-900.

20 Fourrier-Reglat A, Droz-Perroteau C, Benichou J, Depont F, Amouretti M, Begaud B, Moride $Y$, Blin P, Moore N. Impact of prescriber nonresponse on patient representativeness. Epidemiology 2008; 19: 186-90.

21 Czernichow $P$, Hochain $P$, Nousbaum JB, Raymond JM, Rudelli A, Dupas JL, Amouretti M, Gouerou H, Capron MH, Herman $\mathrm{H}$, Colin R. Epidemiology and course of acute upper 
gastro-intestinal haemorrhage in four French geographical areas. Eur J Gastroenterol Hepatol 2000; 12: 175-81.

22 Moride Y, Abenhaim L. Evidence of the depletion of susceptibles effect in non-experimental pharmacoepidemiologic research. J Clin Epidemiol 1994; 47: 731-7.

23 Bresalier RS, Sandler RS, Quan H, Bolognese JA, Oxenius B, Horgan K, Lines C, Riddell R, Morton D, Lanas A, Konstam MA, Baron JA. Cardiovascular events associated with rofecoxib in a colorectal adenoma chemoprevention trial. N Engl J Med 2005; 352: 1092-102.

24 Baron JA, Sandler RS, Bresalier RS, Lanas A, Morton DG, Riddell R, Iverson ER, Demets DL. Cardiovascular events associated with rofecoxib: final analysis of the APPROVe trial. Lancet 2008; 372: 1756-64.

25 Guess HA, West R, Strand LM, Helston D, Lydick EG, Bergman U, Wolski K. Fatal upper gastrointestinal hemorrhage or perforation among users and nonusers of nonsteroidal anti-inflammatory drugs in Saskatchewan, Canada 1983. J Clin Epidemiol 1988; 41: 35-45.

26 MacDonald TM, Morant SV, Goldstein JL, Burke TA, Pettitt D. Channelling bias and the incidence of gastrointestinal haemorrhage in users of meloxicam, coxibs, and older, non-specific non-steroidal anti-inflammatory drugs. Gut 2003; 52: 1265-70.

27 Moore N. Comment on 'Quantitative estimation of rare adverse events which follow a biological progression: a new model applied to chronic NSAID use' Tramer et al., Pain 2000;85:169-182. Pain 2001; 91:401-2.

28 Kearney PM, Baigent C, Godwin J, Halls H, Emberson JR, Patrono C. Do selective cyclo-oxygenase-2 inhibitors and traditional non-steroidal anti-inflammatory drugs increase the risk of atherothrombosis? Meta-analysis of randomised trials. BMJ 2006; 332: 1302-8.

29 Chen YF, Jobanputra P, Barton P, Bryan S, Fry-Smith A, Harris G, Taylor RS. Cyclooxygenase-2 selective non-steroidal anti-inflammatory drugs (etodolac, meloxicam, celecoxib, rofecoxib, etoricoxib, valdecoxib and lumiracoxib) for osteoarthritis and rheumatoid arthritis: a systematic review and economic evaluation. Health Technol Assess 2008; 12: $1-278$, iii.
30 Tunstall-Pedoe $\mathrm{H}$, Kuulasmaa K, Mahonen M, Tolonen $\mathrm{H}$, Ruokokoski E, Amouyel P. Contribution of trends in survival and coronary-event rates to changes in coronary heart disease mortality: 10-year results from 37 WHO MONICA project populations. Monitoring trends and determinants in cardiovascular disease. Lancet 1999; 353: 1547-57.

31 Tunstall-Pedoe $H$, Vanuzzo D, Hobbs M, Mahonen M, Cepaitis Z, Kuulasmaa K, Keil U. Estimation of contribution of changes in coronary care to improving survival, event rates, and coronary heart disease mortality across the WHO MONICA Project populations. Lancet 2000; 355: 688-700.

32 Arveiler D, Wagner A, Ducimetiere P, Montaye M, Ruidavets JB, Bingham A, Ferrieres J, Amouyel P, Haas B. Trends in coronary heart disease in France during the second half of the 1990s. Eur J Cardiovasc Prev Rehabil 2005; 12: 209-15.

33 Cottel D, Dallongeville J, Wagner A, Ruidavets JB, Arveiler D, Ferrieres J, Bingham A, Marecaux N, Ducimetiere P, Amouyel P. The North-East-South gradient of coronary heart disease mortality and case fatality rates in France is consistent with a similar gradient in risk factor clusters. Eur J Epidemiol 2000; 16: 317-22.

34 Jick SS, Kaye JA, Vasilakis-Scaramozza C, Garcia Rodriguez LA, Ruigomez A, Meier CR, Schlienger RG, Black C, Jick H. Validity of the general practice research database. Pharmacotherapy 2003; 23: 686-9.

35 Renaud S, de Lorgeril M. Wine, alcohol, platelets, and the French paradox for coronary heart disease. Lancet 1992; 339: 1523-6.

36 Umar A, Guerin V, Renard M, Boisseau M, Garreau C, Begaud B, Molimard M, Moore N. Effects of armagnac extracts on human platelet function in vitro and on rat arteriovenous shunt thrombosis in vivo. Thromb Res 2003; 110: $135-40$.

37 Moride Y, Ducruet T, Boivin JF, Moore N, Perreault S, Zhao S. Prescription channeling of COX-2 inhibitors and traditional nonselective nonsteroidal anti-inflammatory drugs: a population-based case-control study. Arthritis Res Ther 2005; 7: R333-42. 